\title{
The architectural output between knowledge and science "An analytical vision study in practice to evaluate the products of architecture"
}

\author{
Ibrahim Jawad ${ }^{\mathrm{a}}$, Abdullah Saadoon ${ }^{\mathrm{a}}$ and Tuqa Mahmood $^{\mathrm{b}}$ \\ ${ }^{a}$ University of Technology / Department of Architecture \\ ${ }^{b}$ The Ministry of Construction, Housing, Municipalities and Public Works - Engineering Construction office \\ ibrahimc4-11@yahoo.com
}

\begin{abstract}
The research deals with the concept of architectural knowledge as one of the influences in the process of architectural design, as the nature of the designer and trends in the lure of knowledge derived from the reality of society through successive historical periods have the greatest impact on his ideas, and the nature of the output achieved requires that the architecture exceeds the local boundaries to the site boundaries. It is reflected in its results, thus determining the research problem in (The insufficient knowledge perception available about the architectural product between the duality of knowledge and knowledge thereof). The goal of research to clarify the mechanisms of knowledge of architectural production as well as their characteristics and dimensions. Accordingly, the research assumes that their indicators have a positive impact on the formulation of architectural output. In order to address the research issue and achieve the objectives of the research and verify its hypothesis, a knowledge framework was first constructed, then a comprehensive theoretical framework was extracted from the architectural and supporting propositions to be finalized in three main indicators, namely: "Mechanisms of knowledge of architectural production, characteristics of architectural knowledge of production, and dimensions of architectural knowledge. Finally, a number of conclusions have been reached which provided that the knowledge of architecture as a product is linked to the three knowledge "Galali, Aesthetic, and Kemalism", as well as a correlation between Cognitive characteristics of the architectural product of the port and its dimensions, as it was associated with absorption of production through the cash situation dealt with by man shall his reign began on what is watching from the output characteristics of the port structure with a reflective surface to remove him deep knowledge inherent in the structure.
\end{abstract}

Keywords: Architectural output, knowledge, science.

\section{Introduction}

Knowledge is an effective tool in facilitating architecture as it raises its quality and adjusts its overall indicators according to logical mental processes sequential and formed with other knowledge systems, whether internal or external surrounding. While concerned with the knowledge of the architectural product implemented in terms of what it is the rules of formation and principles of organization as well as the indications indicative of extrapolation. Several studies, in particular in the field of architecture, dealt with the concepts of knowledge and science, but they dealt with architectural knowledge and science with the architectural product implemented concisely or implicitly. Design and implementation practices; So, the search problem was (The insufficient knowledge perception available about the architectural product between the duality of knowledge and knowledge thereof). Therefore, the goal of research to clarify the mechanisms of knowledge of architectural production as well as their characteristics and dimensions.

\section{Research Methodology}

The achievement of the research objectives necessitated the adoption of a descriptive and analytical approach to scientific knowledge from previous studies and applied practices related to the subject of the research within a serial structure that 
included four axes, the first of which was to build the cognitive framework, and the second focused on building the theoretical framework through the analysis of the literature and previous studies, and the third: it addressed the elected projects For the purpose of implementation, Fourth and Last: It includes putting forward conclusions and recommendations.

\section{The first axis: the knowledge framework for research:}

The theme discusses the concepts of architectural knowledge and science of architectural productions in an attempt to understand their meaning and impact on output.

\subsection{The concept of knowledge}

The paragraph describes knowledge from two main aspects:

\subsubsection{Knowledge of language and terminology}

Knowledge can be defined by two main aspects: linguistic custom and gratitude, i.e., ignorance. The term is "all mental processes in the individual; from the perception, learning, thinking and judgment issued by the individual interacting with his own world" [1].

\subsubsection{Knowledge in Architecture}

It is the ability of the architect to learn and acquire skills and embodied in his products Michel Zach classifies architectural knowledge by the level of knowledge to "substantial, advanced, and innovative", while nonak classified by accessibility to "virtual, implicit" while classified BART sourced to "internal, external" [2]. From the above, the procedural definition of the concept of architectural knowledge can be presented as "data and information directed to the designer's mind that is organized, processed, proven and implemented in a specific product.

\subsection{The concept of science}

The paragraph describes science from two main aspects, namely:

\subsubsection{Science is a language and terminology}

Science can be defined in two main aspects: linguistic from the act of science, which is the realization of the thing as it is a real realization. The term is "the format of accumulated scientific knowledge containing a set of principles and rules that explain phenomena and their relationships" [3].

\subsubsection{Science in architectural output}

It is the systematic investigation of a product in order to derive a set of facts such as the rules of its formation and principles of organization, which adds knowledge about what this product or solve a specific problem in it, as well as giving the architect a set of dimensions and interpretive characteristics of the output and other generative. Science of architectural product is dynamic and subject to historical development [4]. From the above, the procedural definition of the concept of architectural production can be put forward as a systematic and objective research and investigation to know the implemented output based on the mechanisms of testing and experimentation to verify the knowledge discovered or refuted or modified.

It is clear from the above that there is a relationship between the two variables, "knowledge, and science"; knowledge is related to the same architecture as the first level of simplified perception, while "science" relates to the production in terms of its mechanisms, dimensions and characteristics as an advanced level of complex cognition, whether the output is implemented or will be implemented in the future, and therefore the cognitive need to develop a comprehensive theoretical conceptualization of the architectural output between knowledge and science has emerged, note the Figure 1.

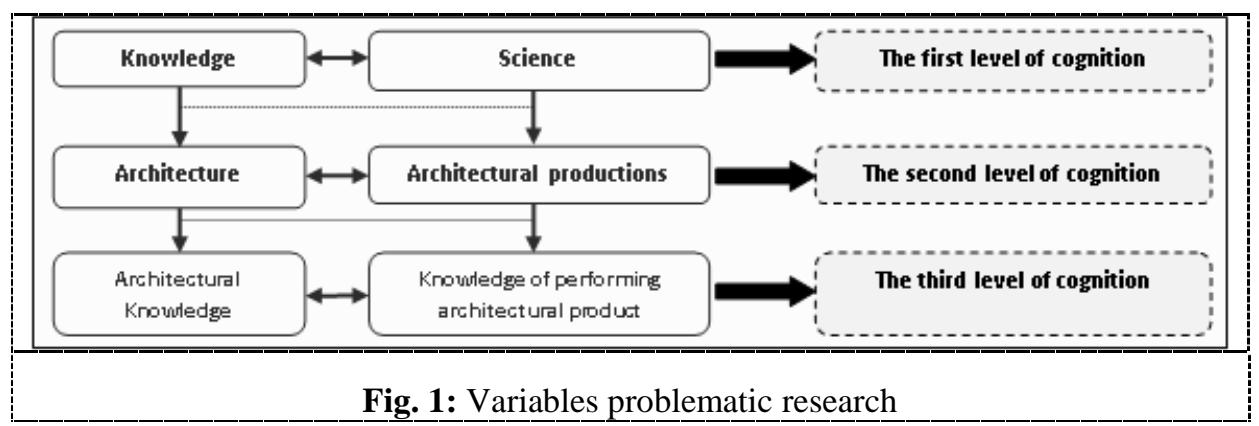




\section{The third axis: building the theoretical framework}

This theme deals with the presentation of a series of previous studies to extract the main and secondary theoretical framework and its possible values.

\subsection{Safárová, Katarína. "Differences between young architects' and non-architects' aesthetic evaluation of buildings", 2019}

The study dealt with two types of factors affecting the process of evaluating the output, one concerned with the evaluator, such as age, gender and cognitive background, and the other concerned with the product as its designer, location and symbolism. The study concluded that there is a positive relationship between the process of evaluating the output and evaluating it, as well as clarifying two types of evaluation mechanisms, namely: First, the general evaluation of the output, which is concerned with the design of the output from the formal, functional, structural, symbolic and colour aspects, as well as the operational and technical aspects, and is adopted in the architectural questionnaire. Secondly, the special evaluation is concerned with the elements of the partial production such as walls, floors, ceilings, doors and windows and is adopted in the public questionnaire [5].We conclude from the above that the study focused on the mechanisms of evaluation of public and private output as well as the factors affecting the evaluation process, showing their impact on the process of evaluating the output.

\subsection{Kurath, Monika Maria. "Architecture as a Science: Boundary Work and the Demarcation of Design Knowledge from Research, 2015}

The study illustrated the dimensions of the formulation of architectural output through cognitive research:

\subsubsection{The ontological dimension}

It is concerned with the practice of architecture according to the frameworks of existential knowledge as it relies on natural and abnormal references embodying the history of human art through simultaneous thinking, modelling and transformations in the two and three-dimensional productions to translate the other.

\subsubsection{Social dimension}

concerned with the practice of architecture in accordance with the contextual knowledge of the community as an influential event in the coordination of design and rehabilitation of harmony with the community, and requires a commitment to situational space and the adoption of technical knowledge in the drafting of architectural texts [6]. We conclude from the above that the dimensions of the luxury knowledge of the architectural product of the designer ontological and social, while the recipient subjective (internal) or external according to the dimensions of knowledge Kemalist output.

\subsection{Mahdavinejad, Mohammadjavad. "Aesthetics and architectural education and learning process", 2014}

The study focused on aesthetic knowledge as it is considered the focal point in the architectural learning and science with its products, pointing out that the mechanisms of the aesthetic knowledge of the product concerned with six elements, namely: It wakes up the feelings in the receiver. Second, the materials, that the construction materials create a compatibility or discrepancy between the building and its environment, which determines the proportion of acceptance or rejection of the public. Third, the location of the building relative to the place determines the degree of attachment or separation as well as the degree of weight (light, heavy) compared to the place containing the product. Fourth, harmony, and means compatibility between all parts of the output, and not limited to the formal dimension (three - dimensional) or space dimension, but exceeds the color, structural and urban compatibility. Fifth, the signs include a set of simple or hidden apparent complex signals that convey a message to the recipient, and related to society, nature, heritage or otherwise. Sixth, decorations are considered as complementary elements. The study shows two characteristics of aesthetic knowledge of production: succession and discipline [7]. It follows from the above that the mechanisms of aesthetic knowledge of the product concerned six elements, namely: "form, materials, place, harmony, signs, and decorations" while their characteristics lie in "sequence, and discipline".

\subsection{Voyatzaki, Maria. "Doctoral Education in Schools of Architecture across Europe", 2014}

The study categorized the dimensions of the architectural knowledge of production according to its type into four categories, namely: planning knowledge, and it is concerned with urban planning policies and strategies at the regional and local levels. Historical knowledge is concerned with the preservation and documentation of architectural heritage in multi-level ways in a single building. Theoretical knowledge, and concerned with the concepts of architectural movements such as modernity, disassociation and digitization as design systems for production. And applied knowledge, and is concerned with practicing architecture in practice, as the implementation stage gives the designer a structural knowledge that is valued for the design and consequently the product. Finally, the study shows that knowledge earns architecture four evaluation skills for production, namely: "thinking skills, technical skills, management skills, construction skills [8]. "We conclude from the above that the study categorized the dimensions of knowledge into four categories, namely: "planning knowledge, theoretical knowledge, and knowledge Historical, and applied knowledge.

DOI:10.52113/3/mjet/2020-8-2/01-07 


\subsection{Marcus, Lars. "The need for theoretical knowledge in architectural practice", 2013}

The study clarified the characteristics of the perfect architectural knowledge adopted in the formulation of the output, namely: "objectivity and exclusivity". The study also distinguishes between two types of products according to the ratio of architectural knowledge and science to production, namely: First, traditional production, which is a product formed as a direct sensory response to the needs inherent in the context, relying on literal knowledge, but it is slow in regeneration as well as its familiar solutions, which generated a different degree of rejection of the production. Secondly, modern production, which is a product formed as a perceptive response to the problems of the societal context, relying on perfection knowledge and formulating new solutions to design problems that simulate or derive from nature and society. The study discusses the stages that constitute the theory of architectural knowledge, namely: the obstetric stage, and is concerned with the production of new ideas. The predictive stage, which is concerned with assessing the ideas applied in the output [5]. We conclude from the above that the study clarified two characteristics of architectural knowledge, namely: "objectivity, and unrestrained," as I discussed the stages of its formation as a theory on the obstetric and predictive phases, so that they are a traditional or modern product according to the mechanisms of knowledge adopted in formulating them.

\subsection{Whyte, J. K., and B. Ewenstein. "Beyond words: aesthetic knowledge and knowing in design", 2007}

The study dealt with the aesthetic knowledge and its derivative mechanisms of thinking as a structured science, explaining the divergence of its mechanisms according to two dimensions: the first sensory, and means that the aesthetic knowledge is a symbolic form of specific and well-established in the deep structure of the architectural production includes non-verbal connotations and references and references reflected their beauty through the surface structure The product is produced by the receiver through the mechanisms of "sensing, intuition, processing, and interpretation" as an underlying aesthetic knowledge. The second is empirical, which means that the aesthetic knowledge is the efficiency of the product formed by the practice compatible with the physical context, including the nature and urbanism, as well as its compatibility with the changing human intangible context and reflected its beauty through interaction as a selective reaction balancing the mutual relationship between them [9]. We conclude from the above that the sensory and experimental dimensions of aesthetic knowledge in terms of style and efficiency are offset by mechanisms of aesthetic reflection of the product through evaluation and response as well as the elements of imagination, contemporary and continuous learning.

\subsection{Brain, David. "Practical knowledge \& occupational control: The professionalization of architecture in the United States", 1991}

The study discusses the relationship between architectural knowledge and professional practice. It determines the rhetorical dimensions of the architectural product, namely: the organizational dimension (proportional), the ideological dimension (intellectual), and the abstract dimension (representative). The study also dealt with the design mechanisms of production according to the architectural knowledge, namely: First, plastic design, where knowledge is a form of organizational control governing the tensions inherent in the internal(structural) of the same product and external relations (communicative) between output and recipient. Second, space design, where knowledge is the regulatory rules for space relations transporter from public to private. Third, the symbolic design, as the knowledge is after my speech linking the building to the society containing him [10]. We conclude from the above that the study expanded the limits of the architectural knowledge of the product to organizational dimensions, ideology and abstraction.

\section{Application}

\subsection{Application to samples}

Application will be applied to architectural specimens of different functional nature in order to find a wide area to indicate the interrelationship between architectural knowledge and science of architectural production and their impact on the formation of the product and its level of acceptance Time.

\subsubsection{Real estate bank building}

A government bank in Baghdad consisting of a basement and eight floors, was designed by the architect Fadhil Ajina and his partners The bank was built in 1975, the architectural knowledge and knowledge of the product to the recipient that the control characteristic rationality on the building; The boundaries are clear, and the similarity in the facades generates confusion for the recipient in determining the facade of the building as it is not felt only when approaching the building and observing its view on the main street. J He disagreed with the usual high buildings, and the weight of the cube compared to a balanced size as it eased the divisions of the optical weight as shown in Figure 2 [11]. 


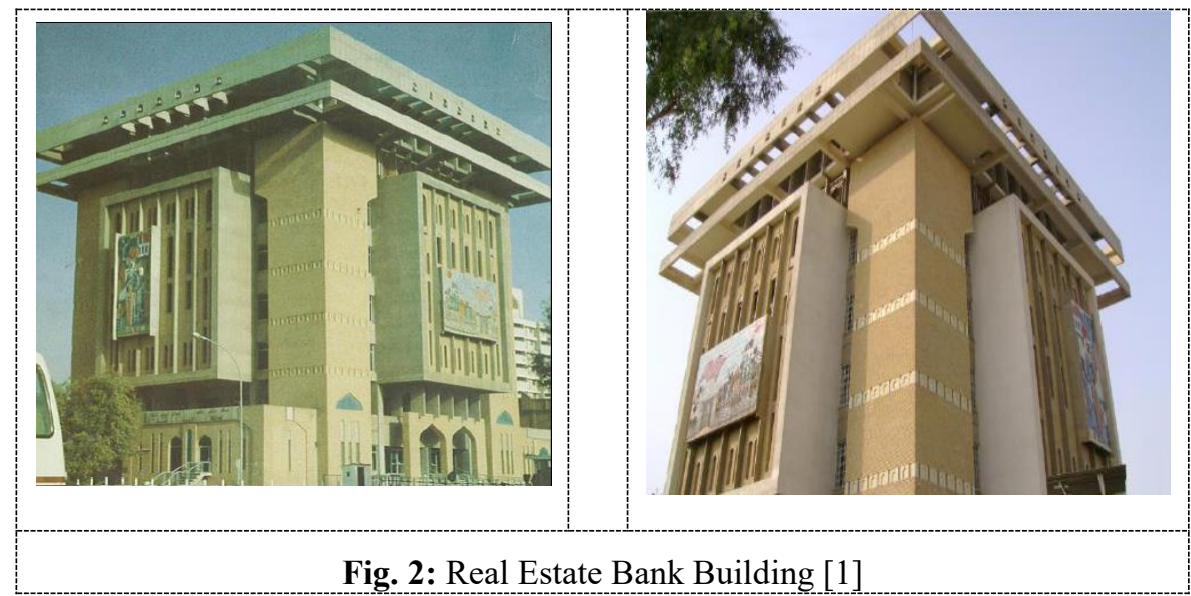

\subsubsection{Ministry of housing and construction building}

The project was started in 2007 by the National Centre for Engineering Consultancy and was completed in 2012. The building consists of ten floors with a height of $43 \mathrm{~m}$. As well as full symmetry as it clearly shows the similarity of the front and side facades, and the design of the facades was based on materials. The formal elements are only areas of aluminium panels and glass with dual function where the panels work as a thermal insulation as well as its role to protect against human threats, has been added colour Blue touch is very much Yeh to the Ministry's building, and notes in the building include the glass surfaces of the three upper floors to mimic the form of so Aelchenhol al-Baghdadi and reflect this heritage in a contemporary [1], as shown in Figure 3.

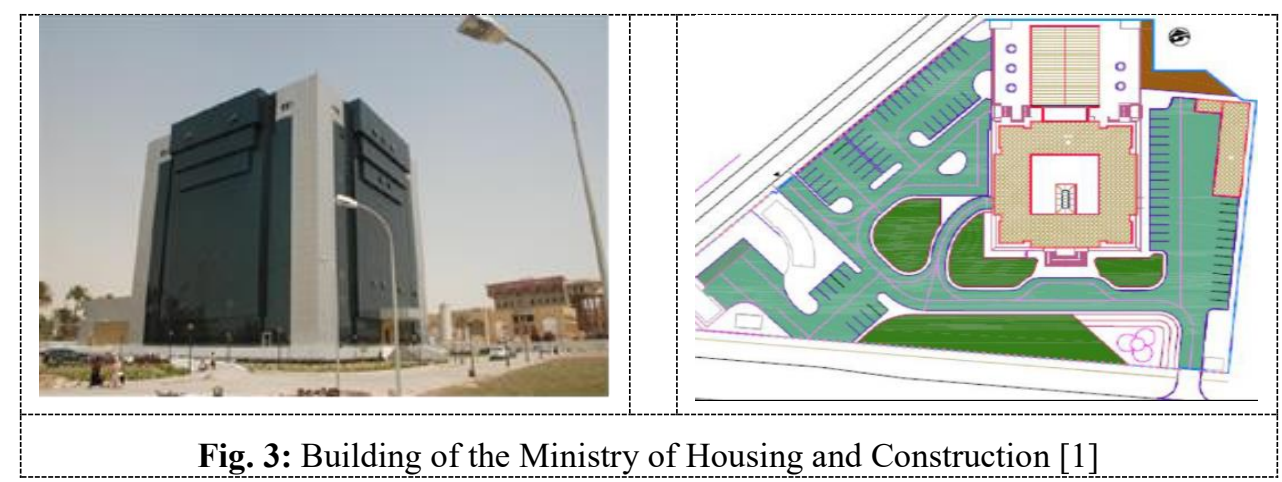

\subsection{Analysis and discussion of the results}

The paragraph explains the most important indication of the results of the application on the selected samples, noting that the evaluation of the effectiveness rate of the main variables according to the equation $\mathrm{T}=\mathrm{Xi} / \mathrm{Yi} * 100 \%$, where $\mathrm{T}$ : the percentage of verification of the individual within the selected samples, Xi: the sum of the achieved values, Yi: the sum of the total values. While the verification of the possible values is tested by direct marking on the table (5-1), which is filled by researchers based on the information extracted for each individual, symbol (2) indicates the value of the variable is achieved by $(100 \%)$, while the symbol indicates (1) indicates that it has achieved (50\%), and the symbol (0) indicates that it has not been achieved by $(0 \%)$.

\subsubsection{The results associated with the individual (Mechanisms of knowledge of architectural production - X1)}

Its percentage $(44 \%)$ and divided into a group of indicators, where the indicators (X.1.2.1-X.1.2.2-X.1.2.3-X.1.2.4-X.1.2.5X.1.2.6-X.1.2.7-X.1.2.8) (100\%) in elected projects, while the percentage of indicators (X.1.2.10-X.1.2.13-X.1.2.14-X.1.2.9) to $(50 \%)$, and no indicators (X.1.1.1-X.1.1.2-X.1.2.12) were found where it came in (0\%), note Table 1. 
Table 1: The main and secondary vocabulary of the theoretical framework, (Source: Researchers)

\begin{tabular}{|c|c|c|c|c|}
\hline Symbol & Possible & values & Secondary vocabulary & Key Vocabulary \\
\hline X.1.1.1 & \multicolumn{2}{|c|}{ Generative mechanisms } & \multirow{2}{*}{$\begin{array}{c}\text { Mechanisms of cognitive } \\
\text { theory formation }\end{array}$} & \multirow{16}{*}{$\begin{array}{l}\text { Knowledge mecha- } \\
\text { nisms of architectural } \\
\text { production } \\
\text { X.1 }\end{array}$} \\
\hline X.1.1.2 & \multicolumn{2}{|c|}{ Predictive mechanisms } & & \\
\hline X.1.2.1 & Degree of juxtaposition & \multirow{4}{*}{$\begin{array}{c}\text { Mechanisms for the for- } \\
\text { mation of architectural } \\
\text { output }\end{array}$} & \multirow{14}{*}{$\begin{array}{c}\text { Mechanisms for the for- } \\
\text { mation of architectural } \\
\text { output }\end{array}$} & \\
\hline X.1.2.2 & Degree of interference & & & \\
\hline X.1.2.3 & Overlay degree & & & \\
\hline X.1.2.4 & Degree of communication & & & \\
\hline X.1.2.5 & Degree of gradient & \multirow[t]{2}{*}{ The space } & & \\
\hline X.1.2.6 & Insulation drawer & & & \\
\hline X.1.2.7 & Degree of compatibility & \multirow[t]{2}{*}{ Materials } & & \\
\hline $\mathrm{X} .1 .2 .8$ & Degree of acceptance & & & \\
\hline X.1.2.9 & Degree of correlation & \multirow[t]{2}{*}{ Place } & & \\
\hline X.1.2.10 & Degree of gravity & & & \\
\hline $\mathrm{X} .1 .2 .11$ & Virtual signals & \multirow[t]{2}{*}{ Tags } & & \\
\hline X.1.2.12 & Hidden signals & & & \\
\hline X.1.2.13 & Binding element & \multirow{2}{*}{ Decking } & & \\
\hline $\mathrm{X} .1 .2 .14$ & Encoding element & & & \\
\hline X.2.1.1 & \multicolumn{2}{|c|}{ Objectivity } & Characteristics of perfec- & \\
\hline X.2.1.2 & \multicolumn{2}{|c|}{ Non-Independence } & tionist knowledge & Characteristics of the \\
\hline X.2.2.1 & \multicolumn{2}{|c|}{ Succession } & Characteristics of aes- & architectural \\
\hline X.2.2.2 & \multicolumn{2}{|c|}{ Discipline } & thetic knowledge & knowledge of the \\
\hline X.2.3.1 & \multicolumn{2}{|c|}{ Balance } & Characteristics of Galilee & $\begin{array}{l}\text { product } \\
\times 2\end{array}$ \\
\hline X.2.3.2 & \multicolumn{2}{|c|}{ Response } & Knowledge & \\
\hline X.3.1.1 & Concurrent thinking & \multirow{3}{*}{$\begin{array}{l}\text { Dimensions of luxury } \\
\text { knowledge }\end{array}$} & \multirow{5}{*}{$\begin{array}{l}\text { Dimensions of luxury } \\
\text { knowledge }\end{array}$} & \multirow{14}{*}{$\begin{array}{l}\text { Dimensions of the ar- } \\
\text { chitectural } \\
\text { knowledge of the } \\
\text { product } \\
\text { X.3 }\end{array}$} \\
\hline X.3.1.2 & Modelling & & & \\
\hline X.3.1.3 & Transitions & & & \\
\hline X.3.1.4 & Situational spacetime & \multirow{2}{*}{ The social dimension } & & \\
\hline X.3.1.5 & Technical knowledge & & & \\
\hline X.3.2.1 & Sensor & \multirow{4}{*}{$\begin{array}{l}\text { Dimensions of aesthetic } \\
\text { knowledge }\end{array}$} & \multirow{6}{*}{$\begin{array}{c}\text { Dimensions of aesthetic } \\
\text { knowledge }\end{array}$} & \\
\hline X.3.2.2 & Intuition & & & \\
\hline X.3.2.3 & Processing & & & \\
\hline X.3.2.4 & Explanation & & & \\
\hline X.3.2.5 & Output compatibility & \multirow{2}{*}{$\begin{array}{l}\text { Experimental dimen- } \\
\text { sion }\end{array}$} & & \\
\hline X.3.2.6 & Efficient output & & & \\
\hline X.3.3.1 & \multicolumn{2}{|c|}{ Organizational dimension (proportional) } & \multirow{3}{*}{$\begin{array}{l}\text { Dimensions of Galali } \\
\text { knowledge }\end{array}$} & \\
\hline X.3.3.2 & \multirow{2}{*}{\multicolumn{2}{|c|}{$\begin{array}{c}\text { The ideological dimension } \\
\text { Abstract dimension (representative) }\end{array}$}} & & \\
\hline X.3.3.3 & & & & \\
\hline
\end{tabular}

\subsubsection{The results associated with the individual (architectural characteristics of output - X2)}

Its percentage $(16 \%)$ and divided into a set of indicators, where the indicators achieved (X.2.1.1-X.2.2.1-X.2.2.2-X.2.3.1) $(100 \%)$ In the selected projects, while there were no indicators (X.2.3.2-X.2.1.2) coming in (0\%).

\subsubsection{Results related to the product (Architectural Knowledge Dimensions of Product - X3)}

Its percentage $(16 \%)$ and divided into a set of indicators, where the indicators achieved (X.2.1.1-X.2.2.1-X.2.2.2-X.2.3.1) $(100 \%)$ In the selected projects, while there were no indicators (X.2.3.2-X.2.1.2) coming in (0\%) as shown in Table 2.

To conclude from the above that knowledge of architectural output and science includes three levels, namely:

- Galilean Knowledge: It means knowing the product in its image and its material in the world of the possible, as the product knows its limits and its vision of the recipient is a building and nothing else.

- Aesthetic knowledge: Knowing the product in the world of possibilities means knowing its essence, its interior, its reality and its effective cause, since the architectural product is defined through the architectural formation and the relationships inherent in it.

- Perfect knowledge: It means the endowment of the very thing in the presence of the possibilities, as the architectural product is defined through the functional program, relationships and three-dimensional composition, which achieves an innovative product. 


\section{Conclusion}

\subsection{Theoretical conclusions}

- Knowledge is the basis of perfection for all those who have the ability to know that the knowledge of those who have a perception only, and the knowledge of architecture as a product has been associated with the three knowledge "Galali, aesthetic, and perfectionism".

- The recipient should be able to produce architecture through multiple levels of knowledge with knowledge of its characteristics to realize, while the designer is concerned with the architectural knowledge and science of production, because of their impact on the adaptation of the output to the environment as well as the development of formulation, which qualifies for social acceptance.

- The research frame the architectural output between knowledge and science in three main indicators, the first of which represents its mechanisms at the two levels, namely: "Mechanisms of forming the epistemological theory of architectural production, and mechanisms of the formation of output", while the second is concerned with the characteristics of architectural knowledge of the product, whether knowledge or aesthetic Kemaliyyah explained, the third dimension as the Galalai knowledge of the production of organizational dimensions, ideology and abstraction, while aesthetic knowledge included two dimensions of sensory and experimental, while Kemaliyah knowledge included the dimensions of the ontological and social.

\subsection{Practical conclusions}

- The results of the application showed the tendency of architects to the mechanism of architectural formation of the product in terms of formation "mass, functional, and structural" and then followed by the design of the place as a treatment of the output implemented at the urban level and finally design marks to give the ideological character of the architectural product implemented, while stepping up the mechanism of forming the epistemological theory of architectural product Despite its importance as it is the source of the establishment of architectural movements.

- There is a correlation between the cognitive characteristics of the implemented architectural product and its dimensions, as the absorption of output was linked through the monetary situation in which the human being dealt with so that his judgment began on what he sees of the characteristics of the implemented output as a superficial structure reflective of its cognitive dimensions inherent in its deep structure.

\section{Recommendations}

- The research recommends the architectural departments to activate the cognitive integration of the architectural production, as what came in the research enhances the students 'awareness of the production in a majestic and aesthetic manner in an attempt to reach perfectionism.

- The research recommends the continuous development of indicators of architectural knowledge and knowledge of the implemented architectural product based on the extraction of knowledge from previous failures and theoretical and practical studies.

- The research recommends the need to expand the other cognitive characteristics of the architectural product, especially the response as a property characteristic, despite its simplicity, but it is the first identification feature of the architectural product implemented.

\section{References}

[1] Al-Salem, M.a.S.i., Organization of Organizations - A Study in the Development of Thought in One Hundred Years. 2002, Amman, Jordan: Modern Book House.

Balmisse, G., Knowledge Management and IT Tools. 2003.

Yaqoob, M.A.-B.H., The Islamic Concept of Science and its Impact on Knowledge Management. Journal of Islam in Asia, 2011. 4.

[4] Ezzat, R.M., Architectural Scientific Research and its Role in Solving the Problems of Architectural Identity and Technology Transfer and Informal Housing Construction during the Second Half of the Twentieth Century. Journal of Engineering Sector, 2018. 13(49): p. 81-100.

[5] Marcus, L., The need for theoretical knowledge in architectural practice. 2013. 15(4).

[6] Kurath, M.M., Architecture as a science: Boundary work and the demarcation of design knowledge from research. 2015.

[7] Mahdavinejad, M., R. Bahtooei, S.M. Hosseinikia, M. Bagheri, A.A. Motlagh, F.J.P.-S. Farhat, and B. Sciences, Aesthetics and architectural education and learning process. 2014. 116: p. 4443-4448.

[8] Voyatzaki, M., Doctoral Education in Schools of Architecture across Europe. 2014, European Network of Heads of Schools of Architecture.

[9] Whyte, J., Beyond words: aesthetic knowledge and knowing in design. 2007. 28(5): p. 689-708.

[10] Brain, D. Practical knowledge and occupational control: The professionalization of architecture in the United States. in Sociological Forum. 1991. Springer.

[11] Al-Jubouri, Z.A., Waqar in Architecture (Characteristics of Waqar Act in the Form of Architectural Productions, in Department of Architecture. 2018, University of Technology: University of Technology, Baghdad, Iraq. 